\title{
Health, demographic change and well- being: the European Union's Horizon 2020 Programme and System Dynamics
}

Article

Accepted Version

Lane, D. C., Pala, Ö. and Barlas, Y. (2015) Health, demographic change and well-being: the European Union's Horizon 2020 Programme and System Dynamics. Systems Research \& Behavioral Science, 32 (4). pp. 407-413. ISSN 1092-7026 doi: https://doi.org/10.1002/sres.2333 Available at https://centaur.reading.ac.uk/40884/

It is advisable to refer to the publisher's version if you intend to cite from the work. See Guidance on citing.

Published version at: http://dx.doi.org/10.1002/sres.2333

To link to this article DOI: http://dx.doi.org/10.1002/sres.2333

Publisher: John Wiley \& Sons

All outputs in CentAUR are protected by Intellectual Property Rights law, including copyright law. Copyright and IPR is retained by the creators or other copyright holders. Terms and conditions for use of this material are defined in the End User Agreement.

www.reading.ac.uk/centaur 
Central Archive at the University of Reading

Reading's research outputs online 


\title{
Repository Note
}

This document is the accepted version of the following article:

Lane, D. C., Ö. Pala and Y. Barlas. 2015. Editorial - Health, Demographic Change, and Well-being: The European Union's Horizon 2020 Program and System dynamics. Systems Research and Behavioral Science 32(4): 407413

which has been published in final form at:

http://onlinelibrary.wiley.com/doi/10.1002/sres.2333/full

Note that the published version may have some differences from the version here. In all cases, the published version takes precedence.

If you wish to cite the ideas in this paper then please cite the version published in SR\&BS, NOT this version.

Please contact the Corresponding Author if you have any queries.

\section{Guest Editorial}

\section{Health, Demographic Change, and Well-being: The European Union's Horizon 2020 Program and System dynamics}

\author{
Selected papers from the Sixth European System Dynamics Workshop, \\ at Koç University, Istanbul, Turkey \\ David C. Lane ${ }^{*}$, Özge Pala ${ }^{2}$ and Yaman Barlas ${ }^{3}$ \\ Henley Business School, England \\ Koç University, Istanbul, Turkey \\ Boğaziçi University, Istanbul, Turkey
}

\section{INTRODUCTION}

This special issue of Systems Research and Behavioral Science concentrates on the use of system dynamics-based analysis (Forrester, 1961; Lane, 1997; Barlas, 2002). To use the framework of Richardson (1991), the system dynamics approach grew out of a 'servomechanisms thread' in feedback thinking. This contrasts with the 'cybernetics thread', from which a rather larger contingent of systems approaches developed (ibid.). System dynamics

\footnotetext{
Correspondence to: Prof David C Lane, Henley Business School, Whiteknights, Reading, RG6 6UD, England. E-mail: d.c.lane@ henley.ac.uk
} 
was also originally seen not to be part of the Operational Research / Management Science (OR/MS) toolkit, based on Forrester's aspiration to tackle more significant organisational issues than those which then concerned OR/MS, problems that "made the difference between the companies that succeed and those that stagnate or fail" (Forrester, 1968, p. 399). Times have changed. Interest from mainstream system scientists (e.g. Keys, 1988; Jackson \& Keys, 1984) and explorations of connections between the core ideas of system dynamics and emerging areas in OR/MS (Lane, 1994) have seen the field shift significantly in its intellectual connections. Now Forrester has been inducted into the International Federation of Operational Research Societies OR Hall of Fame (Lane, 2006) and system dynamics is, as standard, deemed to fall within the suite of systems approaches (Jackson, 2003).

One indicator of the opening up is this journal's support for the bi-annual workshops held in Europe. The most recent of these was held in Turkey in April 2013 and selected papers emerging from that workshop are the topic of this issue. The focus here is on applications of system dynamics relating to the EU's 'Horizon 2020' program.

\section{A WORKSHOP IN ISTANBUL}

Straddling Europe and Asia in geographical, historical, commercial, mythological and cultural terms, Turkey was a striking gathering place for system dynamicists. The city of Istanbul was founded in 660 BCE as Byzantium, perched on the Bosphorus, the strait that links the Sea of Marmara and the Black Sea. In 330 CE it became Constantinople, the capital of the Eastern Roman Empire and home to the Hagia Sophia, built as a Christian church, changed to a mosque and now a museum, and for almost a millennium the largest enclosed space on Earth. The city continued as the capital of the Byzantine and the Ottoman Empires. From the start of the Ottoman period in the Fifteenth Century the name Istanbul was used, that period producing the stark beauty of the land walls that defended the city and the slender beauty of the Sultan Ahmed, or Blue, Mosque (Sultan Ahmet Camii in Turkish). Today, as a major city of the Turkish Republic, Istanbul is a lively centre of activity embracing manufacturing, trading, shipping, scholarship, and the arts (see Figs. 1).

Figs. 1 (See published version)

Figures 1: Facets of Istanbul - (clockwise from top left) interior of the Hagia Sophia, the Blue Mosque, view of the Bosphorus, a section of the Land Walls

With such a rich history, the workshop was grateful for the support of its two local organisers and hosts.

The first local organiser, and prime host for the meeting, was Özge Pala, of the Business Administration Department of Koç University, Istanbul. Koç University was founded in 1993 as a private, non-profit university, the name deriving from the family foundation that established the University. It is a cross disciplinary research university. As a testament to its research excellence, it has been the second most successful Turkish university in the European Union's Research and Innovation funding programme FP7 (the predecessor of 
Horizon 2020). Koç University has 400 faculty, 5300 students, 22 undergraduate programs, 32 masters programs, and 18 doctoral programs. The College of Administrative Sciences and Economics (CASE) that funded the workshop uses a multidisciplinary approach linking economics, business and international relations in both education and research programs. Internationalization is an important part of the university, both in terms of student and faculty exchange and international research collaboration. Specifically, funding the European System Dynamics Workshop was in line with this internationalization emphasis. Koç University Graduate School of Business offers Masters programs in business, finance, and international relations as well as $\mathrm{PhD}$ in Business Administration (marketing, operations and information systems, quantitative methods, finance, management and strategy) and executive education programs. CASE along with the Graduate School of Business is the first and the only institution in Turkey that holds European Quality Improvement System (EQUIS) accreditation awarded by the European Foundation of Management Development (EFMD). Additionally, it is the Turkish member of CEMS, the Global Alliance in Management Education, or Community of European Management Schools and International Companies.

The second local organiser and host was Yaman Barlas, from the Industrial Engineering Department of Boğaziçi University, Istanbul. Boğaziçi has more than 150 years of experience as an academic institution. Founded in 1863 under the name Robert College as the first American college outside the borders of the USA, it served as a leading international institution of higher learning in the region for over a century. In 1971, the higher education campus of Robert College was converted into a Turkish state university, Boğaziçi University (the name means 'inner Bosphorus', or shores of Bosphorus in the city). The university continues to have strong international ties and has established itself as one of the most prestigious higher education institutions in Turkey and in the region. The language of education has always been English. Currently, about 450 full-time faculty members and 400 teaching and research assistants make up the academic workforce of the university. Total student enrolment is about 14,000. Supported by a long tradition of academic excellence, Boğaziçi University has consistently been the preferred choice of the top Turkish students in the national university entrance examinations. The university is also committed to advanced research and graduate education, yet without compromising its excellence in undergraduate education, recognizing the importance of being an institution in which teaching and research are equally valued.

Fig. 2 (See published version)

Figure 2. Participants at the İstinye campus of Koç University.

The İstinye campus of Koç University, a few kilometres north of Istanbul centre, provided facilities for the workshop itself (Fig. 2). Participants gathered the evening before the workshop and dined slightly south of the campus on the same western bank of the Bosphorus, overlooking the Fatih Sultan Mehmet Bridge. As the sky darkened, the lights on the Eastern bank emerged and participants took advantage of the blankets (Battaniye in Turkish) provided. The chill effectively resisted, participants could look out over the water and 
imagine the ghosts of Jason and his Argonauts travelling northwards up the Bosphorus to Colchis on the Black Sea beyond, in pursuit of the Golden Fleece in Colchis on the Black Sea beyond. Or they could ignore the imagined sounds of oar blades dipping into the water and instead enjoy the exquisite local cuisine and so fortify themselves for the scientific sessions the next day.

Generally following the model of the workshop series, authors first gave a talk on one of their research projects or topics, selected to contribute to the broader theme of the workshop. In each case, a designated discussant then responded with remarks to support, critique and extend. In open session, all participants then posed questions and contributed comments. A total of eight talks were given in this way (Fig. 3).

Fig. 3 (See published version

Figure 3: Enjoying a presentation).

Each of the workshops in the series is designed with its own specific aims in mind and this was no less true of EuSDW-VI. Nevertheless, the guest editors are able to include in this special issue a selection of the ideas and projects discussed at EuSDW-VI in the form of research papers. These were developed further, in part in response to comments from all workshop participants, and also as a result of the journal's refereeing processes. Also presented here are papers by the respective 'discussants' at the workshop, providing a sense of the interplay of ideas at the event itself but offering readers alternative perspectives on the topics of the papers.

A location such as Istanbul, combined with the intellectual heritages of the two host institutions, could not but promote trans-disciplinary thinking amongst the European system dynamicists who were able to gather together via the mechanism of the continuing workshop series. The first of these resulted from the efforts of Peter Milling and Andreas Größler at the Universität Mannheim, Germany in 2003 when they organised and hosted a pan-European meeting of researchers. A special issue of this journal also emerged, the topic being 'Rationality in System Dynamics: Modelling Human and Organizational Decision Making' (Lane, Größler \& Milling, 2004). The year 2005 brought the next workshop at Radboud University, Nijmegen in The Netherlands, with the theme 'System Dynamics in Organizational Consultation: Modelling for Intervening in Organizations' (Lane, Rouwette \& Vennix, 2006). The University of St. Gallen in Switzerland in 2007 played host to a third workshop on 'Theory Building with System Dynamics' with an associated special issue (Lane \& Schwaninger, 2008). Hosted by the University of Palermo, Italy in 2009, the next workshop, had the theme 'Public Sector Applications of the System Dynamics Approach' (Lane, Bianchi \& Bivona, 2010) whilst the fifth focussed on 'Developing Sustainable Strategies with System Dynamics' and took place at the Frankfurt School of Finance \& Management, Germany (Lane, Strohhecker \& Größler, 2012).

The Istanbul meeting was therefore the sixth in a sequence of workshops which afford an opportunity for system dynamics researchers spread across Europe to meet with each other 
and discuss their ideas and work. In this case, the organising theme concerned the European Union's Horizon 2020 Program

\section{HEALTH, DEMOGRAPHIC CHANGE, AND WELL-BEING}

In 2012 the European Commission announced that in 2014 it would launch its new funding program for research and innovation, 'Horizon 2020'. With a budget of $€ 80$ billion, Horizon 2020 reflects the policy priorities of the Europe 2020 strategy and addresses major concerns shared by citizens in Europe and elsewhere ${ }^{1}$. Horizon 2020 has three broad objectives: excellent science, competitive industries, and better societies. It aims to strengthen European research, tackle societal challenges, and bridge the gaps between research, the market and society. The 2013 European SD workshop focused on one of the challenges identified by Horizon 2020: Health, Demographic Change, and Wellbeing. These three areas together comprise a very broad range of societal issues, including: design of effective and costefficient healthcare systems; policies and strategies for happy and healthy aging; and broader components of wellbeing, to be found for instance in ecological, environmental and educational dimensions. The purpose of the workshop was to initiate a discussion amongst the European SD practitioners on the ways in which SD might be incorporated into research proposals for Horizon 2020, particularly the Health, Demographic Change and Wellbeing challenge.

All eight papers invited to and presented at the workshop could be classified naturally into one of the three main challenges above. Some papers were methodological ones illustrated in one of the three areas, others were direct applications on a specific problem from these areas. Among four papers included in this special issue, the first one by Kopainsky et al. (2015) can be classified as a general Wellbeing challenge, the next paper by Nistelrooij et al. (2015) and the third one by Meker and Barlas (2015) both deal more directly with problems of healthcare, and the last paper by Auping et al. (2015) is about a challenge of demographic change.

The interactive nature of the workshop has been discussed earlier. As an aspect of this it is worth recording the fruits of the discussion at the end of the workshop. Two conclusions emerged. The first related directly to the main theme: it was concluded that European system dynamicists had strong potential and experience to write joint grant proposals to Horizon 2020 in the Health, Demographic Change and Well-being program and that participants should start forming suitable networks to this end. The second result - also related to the first was the idea of setting up a European System Dynamics portal where we would all share manuscripts, reports, models, projects, grant information, conferences. Such a portal would not only be a good platform to facilitate networking for grant proposals, but also a central and fixed web site, a 'memory' for all past and future European System Dynamics Workshops.

\footnotetext{
${ }^{1}$ Details of Europe 2020 strategy and the Horizon 2020 program may be found, respectively, at:-

http://ec.europa.eu/europe2020/index_en.htm http://ec.europa.eu/programmes/horizon2020/
} 


\section{CONTENTS OF THIS SPECIAL ISSUE}

As stated above, this special issue presents four research papers in areas relating to the Horizon 2020 Program on the topic of sustainable strategies. Each of these has a set of discussant's comments. After this Guest Editorial, the special issue therefore contains the following:

1. The issue open with the paper 'Food provision and environmental goals in the Swiss agrifood system: System dynamics and the social-ecological systems framework'. Using a System Dynamics model, Birgit Kopainsky, Robert Huber and Matteo Pedercini consider the challenge for the agri-food system in Switzerland of aligning food provision with environmental goals. The Discussant's Comments that follow are by Jim Duggan and provide further support for the authors' argument that System Dynamics can be a powerful pool for analyzing the long term policy questions central to the concerns of Horizon 2020.

2. This is followed by a paper by Lambertus van Nistelrooij, Etiënne Rouwette, Ilse Verstijnen and Jac Vennix. The paper 'The eye of the beholder: A case example of changing clients' perspectives through involvement in the model validation process' describes work for the National Health Care Institute in The Netherlands concerning the sustainable provision of treatment for cataracts. However, their focus is on the processes that were undertaken to build their clients' confidence in the usefulness of the model. The Discussant's Comments by David Lane extend this by describing how System Dynamics notions of model validity that centre on building confidence share core ideas with other simulation, indeed, OR/MS approaches.

3. The third paper is 'Dynamic Consequences of Performance-based Payment Systems in Public Hospitals'. In it, Tuğrul Meker and Yaman Barlas describe the use of System Dynamics to evaluate the effectiveness of a decade-long application of performance management in the healthcare sector in Turkey. Whilst intended to improve healthcare efficiency and control rising costs, the approach is shown to produce unintended and undesirable consequences. Özge Pala provides Discussant's Comments in which she relates this specific lesson to broader experiences of the use of financial incentives and how System Dynamics can aid in the a priori assessment of their effectiveness.

4. The fourth Research Paper is by Willem Auping, Erik Pruyt and Jan Kwakkel. In 'Societal Ageing in the Netherlands: A Robust System Dynamics Approach', these authors study the increasing health costs in The Netherlands associated with aging and consider the fiscal sustainability of a system confronting declining productivity levels and increasing life expectancy. In his Discussant's Comments, Carmine Bianchi generalises this experience and considers the links to ideas of joined up government and the contribution that System Dynamics can make in the area of public administration when such 'wicked problems' arise. 
The Afterword by Andreas Größler reflects on the Workshop and brings the special edition to a close.

We very much hope that this collection will interest researchers and practitioners in system dynamics, system science, OR/MS, healthcare management, and all other application domains relating to Horizon 2020.

\section{ACKNOWLEDGEMENTS}

The guest editors would like to offer their thanks to all who made this special edition possible:-

All those whose organisational efforts lead to the smooth running in 2013 of the EuSDWVI workshop.

Those who anonymously acted as referees for this special edition. The refereeing process drew on the world-wide community of systems science, operational research and system dynamics researchers and we are grateful to them for their vital assistance.

Janet Larkin of the Department of Coin and Medals and Lesley Fitton of the Department of Greek and Roman Antiquities, both of the British Museum, London provided the image upon which the symbol used for the workshop series is based. The owl is taken from the reverse side of a silver tetradrachm made in Athens around 480 BC. CM 1906-11-3-2591. Copyright British Museum, London. The Athenian owl symbol for the series of European System Dynamics Workshops was designed and created by David Lane.

What is now thought of as the first European System Dynamics Workshop in Mannheim in March 2003 was the work of Andreas Größler and Peter Milling. We are grateful to them for their creation of a sound format for the workshops.

Finally, Mike Jackson and Amanda Gregory for inviting us to produce the special issue and for their constant support for the European System Dynamics workshops.

\section{REFERENCES}

Auping WL, Pruyt E and Kwakkel JH. 2015. Societal Ageing in the Netherlands: A Robust System Dynamics Approach. Systems Research and Behavioral Science 32: 485-501.

Barlas Y. 2002. System Dynamics: Systemic Feedback Modeling for Policy Analysis. In Knowledge for Sustainable Development - An Insight into the Encyclopedia of Life Support Systems Vol.1 UNESCO-Eolss Publishers: Paris; pp. 1131-1175.

Forrester JW. 1961. Industrial Dynamics. MIT Press: Cambridge, MA.

Forrester JW. 1968. Industrial Dynamics - After the first decade. Management Science 14: 398-415.

Jackson MC. 2003. Systems Thinking: Creative holism for managers. Wiley: Chichester. Jackson MC and Keys P. 1984. Towards a system of system methodologies. Journal of the Operational Research Society 35: 473-486. 
Keys P. 1988. System Dynamics: A methodological perspective. Transactions of the Institute of Measurement and Control 10: 218-224.

Kopainsky B, Huber R and Pedercini M. 2015. Food provision and environmental goals in the Swiss agri-food system: System dynamics and the social-ecological systems framework. Systems Research and Behavioral Science 32: 414-432.

Lane DC. 1994. With A Little Help From Our Friends: How system dynamics and 'soft' OR can learn from each other. System Dynamics Review 10: 101-134.

Lane DC. 1997. Invited Review and Reappraisal: 'Industrial Dynamics' by Jay W. Forrester. Journal of the Operational Research Society 48: 1037-1042.

Lane DC. 2006. IFORS' Operational Research Hall of Fame - Jay Wright Forrester. International Transactions in Operational Research 13: 483-492.

Lane DC, Bianchi C and Bivona E (eds.). 2010. Public Sector Applications of the System Dynamics Approach: Selected papers from the fourth European system dynamics workshop, at University of Palermo, Italy. 27(4): Special Edition of the international journal Systems Research and Behavioral Science.

Lane DC, Größler A and Milling PM (eds.). 2004. Rationality in System Dynamics: Selected papers from the first European system dynamics workshop, Mannheim University. 21(4): Special Edition of the international journal Systems Research and Behavioral Science.

Lane DC, Rouwette EAJA and Vennix JAM (eds.). 2006. System Dynamics in Organizational Consultation: Modelling for Interventions in Organizations (Selected papers from the second European system dynamics workshop, Radboud University Nijmegen). 23(4): Special Edition of the international journal Systems Research and Behavioral Science.

Lane DC and Schwaninger M (eds.). 2008. Theory Building with System Dynamics (Selected papers from the third European system dynamics workshop, University of St. Gallen, Switzerland). 25(4): Special Edition of the international journal Systems Research and Behavioral Science.

Lane DC, Strohhecker J and Größler A (eds.). 2012. Developing Sustainable Strategies with System Dynamics: Selected papers from the fifth European system dynamics workshop, Frankfurt School of Finance \& Management, Germany. 29(6): Special Edition of the international journal Systems Research and Behavioral Science.

Meker T and Barlas Y. 2015. Dynamic Consequences of Performance-based Payment Systems in Public Hospitals. Systems Research and Behavioral Science 32: 459-480.

Nistelrooij LPJv, Rouwette E, Verstijnen I and Vennix JAM. 2015. The Eye of the Beholder: A case example of changing clients' perspectives through involvement in the model validation process. Systems Research and Behavioral Science 32: 437-449.

Richardson GP. 1991. Feedback Thought in Social Science and Systems Theory. Univ. Pennsylvania: Philadelphia. 
N.B. This list of contents is not part of the Editorial but is provided here for reference

\title{
Health, Demographic Change, and Well-being: The European Union's Horizon 2020 Programme and System Dynamics
}

\author{
Selected papers from the Sixth European System Dynamics Workshop, \\ at Koç University, Istanbul, Turkey
}

Guest Editors: David C. Lane, Özge Pala and Yaman Barlas

\section{Contents of the Special Issue}

Systems Research and Behavioral Science, 2015, Volume 32 Number 4

407 Guest Editorial: Health, Demographic Change and Well-Being: The European Union's Horizon 2020 Programme and System Dynamics - D. C. Lane, Ö. Pala and Y. Barlas

414 Food Provision and Environmental Goals in the Swiss Agri-Food System: System Dynamics and the Social-ecological Systems Framework - B. Kopainsky, R. Huber and M. Pedercini

433 System Dynamics and Social-Ecological Systems Framework: Complimentary Methods for Exploring the Dynamics of Complex Systems - J. Duggan

437 The Eye of the Beholder: A Case Example of Changing Clients' Perspectives Through Involvement in the Model Validation Process - L. P. J. van Nistelrooij, E. A. J. A. Rouwette, I. M. Verstijnen and J. A. M. Vennix

450 Validity is a Matter of Confidence-But Not Just in System Dynamics - D. C. Lane

459 Dynamic Consequences of Performance-Based Payment Systems in Public Hospitals T. Meker and Y. Barlas

481 Pay-for-performance Plans - Ö. Pala

485 Societal Ageing in the Netherlands: A Robust System Dynamics Approach - W. L. Auping, E. Pruyt and J. H. Kwakkel

502 Enhancing Joined-Up Government and Outcome-Based Performance Management through System Dynamics Modelling to Deal with Wicked Problems: the Case of Societal Ageing - C. Bianchi

506 Afterword - A. Größler 